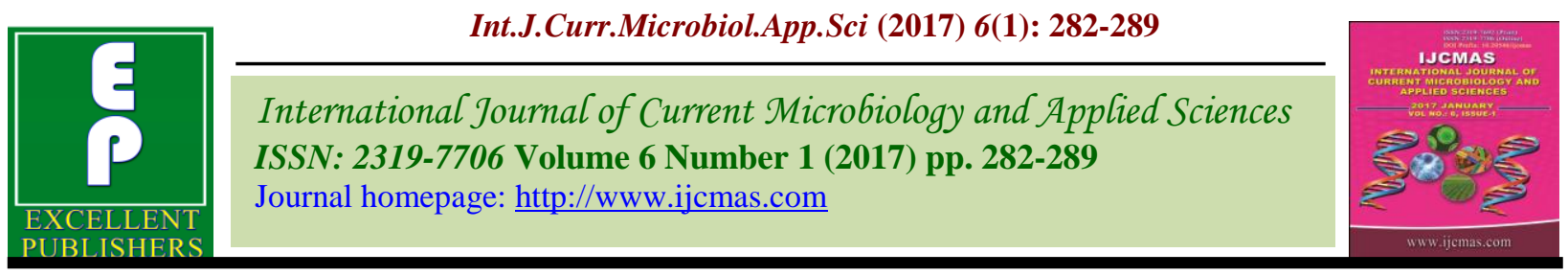

Original Research Article

http://dx.doi.org/10.20546/ijcmas.2017.601.034

\title{
Assessment of Probiotic Potential of Lactic Acid Bacteria Isolated from Curd and its Application using Fruit Juice
}

\author{
Subi Mathew*, Sneha Vijay and V.P. Potty \\ Department of Biotechnology, CEPC Laboratory and Technical Division \\ Mundakkal West, Kollam, India \\ *Corresponding author
}

\begin{tabular}{|c|c|}
\hline & A B S T R A C T \\
\hline $\begin{array}{l}\text { K e y w o r d s } \\
\text { Lactic acid } \\
\text { bacteria, } \\
\text { Probiotics, } \\
\text { tolerance, } \\
\text { Shelf life. }\end{array}$ & \multirow{3}{*}{$\begin{array}{l}\text { Probiotics are a group of microorganisms that when administered in adequate amounts, } \\
\text { confer a health benefit on the host. They build up health effects by number of ways viz. } \\
\text { improving immune function, enhancing proper digestion, fighting against pathogens etc. } \\
\text { Various species are proved to possess probiotic properties. Most important is that the } \\
\text { selected probiotic strain must be able to survive in human gut, as the gut offers a difficult } \\
\text { environment. In the present study, lactic acid bacteria was isolated from curd and its } \\
\text { probiotic potentials were evaluated. Studies were carried out to isolate and identify } \\
\text { microorganisms for probiotic use. Selection of strains included various criteria such as } \\
\text { agreement with biosafety aspects, viability during storage, tolerance to low pH, tolerance } \\
\text { to bile salt and antimicrobial activity. Using fruit juice, its shelf life was determined in } \\
\text { order to estimate the survival ability. It was evidently proved that the cultures remained } \\
\text { viable over a period of time and inhibited the growth of pathogenic growth. Extensive } \\
\text { studies on mechanisms of probiotic activities may enable their new medical applications. }\end{array}$} \\
\hline Article & \\
\hline $\begin{array}{l}\text { Accepted: } \\
\text { 18 December } 2016 \\
\text { Available Online: } \\
10 \text { January } 2017\end{array}$ & \\
\hline
\end{tabular}

\section{Introduction}

Nowadays, health has become a major concern in the growing world. As our lifestyle meets modernization, it is no matter of doubt that our food style also gets modified. The acceptance of this modern is certainly bring health related consequences. Under the present circumstance, something that boost up our health is a topic of interest. Probiotics are defined as live microbial food ingredients that have a beneficial effect on human health (Salminen et al., 1998). The concept of probiotics evolved at the turn of the 20th century from a hypothesis first proposed by Nobel Prize winning Russian scientist Elie Metchnikoff (Bibel, 1988), who suggested that the long, healthy life of Bulgarian peasants resulted from their consumption of fermented milk products. He believed that when consumed, the fermenting bacillus (Lactobacillus) positively influenced the micro flora of the colon, decreasing toxic microbial activities. The word "probiotic" (origins: Latin pro meaning "for" and Greek bios meaning "life") was first used in 1954 to indicate substances that were required for a healthy life.

Out of a number of definitions, the most widely used and accepted definition is that proposed by a joint $\mathrm{FAO} / \mathrm{WHO}$ panel 
(FAO/WHO, 2001): "Live micro-organisms which, when administered in adequate amounts, confer a health benefit on the host".

In the recent years, researchers have focused on many bacteria to assess their probiotic potential. Among all, Lactic acid bacteria (LAB) play an important role in the production of probiotics. LAB comprises a wide range of genera and include a considerable number of species. These bacteria are the major component of the starters used in fermentation, especially for dairy products and some of them are also natural components of the gastrointestinal microflora. Lactobacillus is one of the most important genera of LAB (Coeuret et al., 2003). Others include Lactococcus, Bifidobacterium, Enterococcus etc.

During the last 15 years, the Lactobacillus genus has evolved and contains to date more than 80 species. They are present in raw milk and dairy products such as cheeses, yoghurts and fermented milks. LAB comprises a large and diverse group of Gram positive, nonspore forming, catalase negative bacteria able to produce lactic acid as the main end product of the fermentation of carbohydrates (Pelinescu et al., 2009). They are considered as generally recognized as safe (GRAS) organisms and can be safely used as probiotics for medical and veterinary applications (Fuller, 1989). Bacteria belonging to Lactobacillus and Bifidobacteria groups are typically found in many probiotic products for human and animal use.

\section{Materials and Methods}

\section{Isolation of lactic acid bacteria}

Curd sample was collected for the isolation of lactic acid bacteria (LAB). The sample was stored in $4^{0} \mathrm{c}$ to protect from contamination and deterioration.
Lactic acid bacteria was isolated from curd sample by using modified MRS (Himedia) agar. The $\mathrm{pH}$ of the media was adjusted to 6.5. Isolation was carried out using spread plate technique. $10^{-1}$ and $10^{-2}$ dilutions were used. The plates were incubated at $37^{\circ} \mathrm{c}$ for 24-48hrs.

\section{Characterization}

The isolated bacteria was identified by various tests viz., gram's staining, catalase test, motility test and biochemical tests.

\section{Probiotic properties of isolate}

\section{Resistance to low pH}

The ability to survive in low $\mathrm{pH}$ is considered as one of the important property of probiotic bacteria. Resistance to $\mathrm{pH} 3$ is often used in invitro assays to determine the resistance to stomach $\mathrm{pH}$. For this purpose, the organism was grown in MRS broth. Cells were harvested by centrifugation at 5000rpm for 10minutes. Supernatant was discarded and the pellet was washed with PBS buffer pf pH7.2. Then pellet was re-suspended in PBS buffer of $\mathrm{pH} 2.8$ and again centrifuged at 5000rpm for 10 minutes. The pellet was mixed with 50ml PBS (pH2.8). Viable micro-organisms were enumerated at the $0,1,2$, and 3hour using pour plate technique. Also growth was monitored by measuring O.D at $620 \mathrm{~nm}$.

\section{Tolerance against Bile}

The organism was grown in MRS broth. The broth was centrifuged at 5000rpm for 10minutes. Supernatant was discarded; pellet was washed and re-suspended in PBS buffer (pH7.2). Then again centrifuged at 5000rpm for 10minutes. After removing the supernatant, pellet was mixed with MRS broth supplemented with bile salt (0.3\%). Viable bacterial count was enumerated using 
pour plate technique at $0,1,2,3$ and 4 hours. Growth was monitored by measuring O.D at $620 \mathrm{~nm}$.

\section{Anti-Microbial Activity}

Modified agar well diffusion method was used to detect antimicrobial activity of the isolate. Antibacterial activity was determined against Salmonella enteritidis, Staphylococcus aureus, Vibrio cholerae, Listeria monocytogenes.

These indicator organisms were swabbed onto the sterile MHA (Muller Hinton Agar) plate using swab. Using sterile tip, the broth culture of LAB was poured into the well of about $50 \mu \mathrm{l}$ and kept for incubation at $37^{\circ} \mathrm{c}$ for $24 \mathrm{hrs}$. Anti-microbial activity was evaluated by measuring the zone of inhibition against the test organism.

\section{Gelatinase Activity}

A heavy inoculum of $18-24 \mathrm{hr}$ old culture of bacteria is inoculated using a stab into tubes containing nutrient gelatin. The tubes were incubated at $25^{\circ} \mathrm{c}$ for 3-4 days. A tube inoculated with staphylococcus aureus was kept as positive control.

\section{Blood Hemolysis}

This test is performed to check whether the organism is hemolytic or not. The hemolytic activity was determined according to Guttmann and Ellar (2000). Isolates were screened on freshly prepared sterile blood agar plates containing 5\%blood and plates were streaked with $16-18 \mathrm{hrs}$ old culture and incubated at $37^{\circ} \mathrm{c}$ for $24-48 \mathrm{hrs}$. They were observed for clear zones surrounding the colonies(positive reaction for $\beta$-hemolysis).

Bile Esculin Test: The organism was streaked onto bile esculin agar slants. The tubes were incubated at $37^{\circ} \mathrm{c}$ for 24 hours.

\section{Physiological characterization}

\section{Growth at different temperatures}

Temperature test media, i.e. MRS containing bromocresol purple indicator was prepared and transferred into tubes as $5 \mathrm{ml}$. then $50 \mu \mathrm{l}$ of overnight culture was inoculated to tubes and incubated for 7 days at $10^{\circ} \mathrm{c}, 15^{\circ} \mathrm{c}$ and $45^{\circ} \mathrm{c}$. During this incubation time, cell growth at any temperature was observed by the change of the color from purple to yellow.

\section{Growth at Different Nacl Concentrations}

Isolate was tested for their tolerance against different $\mathrm{NaCl}$ concentrations. $4 \%$ and $6.5 \%$ $\mathrm{NaCl}$ concentrations were selected. Test medium containing bromocresolpurple was prepared according to appropriate concentrations and transferred to tubes as $5 \mathrm{ml}$. the tubes were inoculated with overnight old culture and then incubated at $37^{\circ} \mathrm{c}$ for 7 days. Cell growth was observed by the change of color from purple to yellow.

\section{Arginine Hydrolysis}

Arginine MRS medium and Nessler's reagent are used in order to see ammonia production from arginine. MRS containing $0.3 \%$ Larginine hydrochloride was transferred to tubes as $5 \mathrm{ml}$ and inoculated with overnight culture. Tubes are incubated at $37^{\circ} \mathrm{c}$ for 24hours. After incubation, $100 \mu$ l of cultures are transferred onto white background. Same amount of Nessler's reagent was pipetted on the culture. Change in color was observed. Bright orange color indicates positive reaction, yellow color indicates negative reaction. A negative control without arginine is used as control.

\section{Antibiotic Sensitivity}

The antibiotic resistance of the isolate was assessed using antibiotic discs (Himedia 
HX002IPK) on Mueller Hinton agar plates. The organism was swabbed on the plate and discs were placed on the surface of agar. Resistance was assessed against penicillin G, Erythromycin, Vancomycin ampicillin, cotrimoxazole and clindamycin. The plates were incubated at $37^{\circ} \mathrm{c}$ for 24 hours (Halami et al., 1999).

\section{Biochemical Characterization}

Different biochemical tests like carbohydrate fermentation test, indole test, methyl red, voges-prausker, citrate utilization, nitrate reduction, urease, oxidase, triple sugar iron agar test were carried out and the species biochemical activity was measured.

\section{Shelf life study}

\section{Preparation of substrates}

Ripe mangoes were purchased from the local market in Kollam. The mangoes were washed thoroughly with running tap water, rinsed with distilled water and blotted dry. The peel was removed using sterile knife. The seeds were separated manually from the pulp. Then the juice is then prepared using mixer and it was stained through double fold muslin cloth. The juice is then sterilized and stored at 40c and used as substrate for further studies.

\section{Preparation of Inoculum}

The culture for inoculation is prepared in MRS broth. The LAB culture was inoculated into MRS broth and incubated at $37^{\circ} \mathrm{c}$ for 24hrs. Then the broth was centrifuged at 5000rpm for 10 minutes.

Supernatant was discarded, pellet was washed and re-suspended in PBS buffer of $\mathrm{pH} 7.2$ and again centrifuged (50000 rpm for 10 minutes). Supernatant was discarded and pellet was used for inoculation.

\section{Inoculation on to Substrates}

The $\mathrm{pH}$ of the fruit juice was checked before inoculation and it was found to be 6.8. The cells harvested in the pellet was inoculated into one set of fruit juice $(100 \mathrm{ml})$ aseptically. Another $100 \mathrm{ml}$ juice (uninoculated) was kept as control. $5 \mathrm{gm}$ glucose was added to each set of juice.The inoculated juice sample and the control were stored at $4^{0} \mathrm{c}$ for 4 weeks. Samples were taken at periodic intervals and viability of probiotic culture in juice were determined and expressed as colony forming unit (CFU) using spread plate technique.

\section{VITEK Identification}

The VITEK is a fully automated bacterial identification and antibiotic susceptibility system that uses fluorescent technology to provide broad profiles for the reliable identification of the most relevant organisms. The isolated species was identified using VITEK II system.

\section{Results and Discussion}

Isolation and characterization: MRS agar plates streaked with curd sample showed small, entire, creamy white, opaque Colonies. On Gram's staining, colonies appear as Gram positive cocci arranged in linear fashion. The organism was found to be non-motile. Colonies were catalase negative as no bubbles were formed on addition of hydrogen peroxide.

\section{Probiotic properties of isolate}

\section{Resistance to low ph}

After incubation, optical density of the sample was measured at $620 \mathrm{~nm}$ and viable cell count was determined. From which it is clear that the isolate was able to survive in $\mathrm{pH} 3$ for 3hours. A significant increase in O.D value was observed during the interval. Hence it was concluded that the LAB isolate was tolerant to low $\mathrm{pH}$. 
Table.1

\begin{tabular}{|l|l|l|}
\hline Time & O.D at 620nm & CFU per ml \\
\hline $0^{\text {th }}$ hour & 0.350 & TNTC \\
\hline $1^{\text {st }}$ hour & 0.420 & TNTC \\
\hline $2^{\text {nd }}$ hour & 0.510 & TNTC \\
\hline $3^{\text {rd }}$ hour & 0.560 & TNTC \\
\hline
\end{tabular}

Table.2

\begin{tabular}{|l|l|l|}
\hline Time & O.D at 620nm & CFU per ml \\
\hline $0^{\text {th }}$ hour & 0.412 & TNTC \\
\hline $1^{\text {st }}$ hour & 0.596 & TNTC \\
\hline $2^{\text {nd }}$ hour & 0.821 & TNTC \\
\hline $3^{\text {rd }}$ hour & 1.080 & TNTC \\
\hline $4^{\text {th }}$ hour & 1.255 & TNTC \\
\hline
\end{tabular}

\section{Tolerance against bile}

The viable cells were determined by measuring O.D at $620 \mathrm{~nm}$ and was expressed as Colony forming units. Based on the results, the isolate was found to tolerate bile salt.

\section{Antimicrobial activity}

The activity was determined against 4 organisms. All of which are pathogenic for humans. From the result it was observed that the LAB isolate was found to inhibit the growth of all indicator organisms for a certain extend. The zone size was measured and recorded .Salmonella typhimurium- $11 \mathrm{~mm}$, Listeria monocytogenes- $15 \mathrm{~mm}$, Vibrio choler- 12mm, Staphylococcus aureus $10 \mathrm{~mm}$

Gelatinase activity: The inoculated tubes remained solid, hence the isolate was gelatinase negative. The isolate does not produce the enzyme gelatinase.

Blood hemolysis: The blood agar plate streaked with LAB was found to be unchanged. There was no zone of hemolysis around the colonies. They are non-hemolytic and belong to $\Upsilon$ hemolytic group.

Bile esculin test: The inoculated tube produced a black coloration, which indicates positive result. This test is used to identify the ability of bacteria to hydrolyze esculin in the presence of bile.

\section{Physiological Characterization}

Growth at different temperatures: Tubes incubated at $10^{\circ} \mathrm{C}$ and $15^{\circ} \mathrm{c}$ produced color change from purple to yellow. This indicates growth of the organism. As the organism produces lactic acid, the color of the medium was changed. In the tube incubated at $45^{\circ} \mathrm{c}$, no change was observed.

\section{Growth at different $\mathrm{NaCl}$ concentrations:}

The isolate was tested against 2\%, $4 \%$ and $6.5 \% \mathrm{Nacl}$ concentrations. The organism was able to tolerate all the three concentrations. So it was concluded that growth of the isolate was not inhibited by $\mathrm{NaCl}$.

Arginine hydrolysis: After incubation, the culture was transferred to white background 
and Nessler's reagent was added. Bright orange color was observed, which indicates positive result. the plates containing discs showed specific zone size. By comparing it with Kirby- Bauer chart, the results were interpreted.

Antibiotic sensitivity test: After incubation,

Table.3

\begin{tabular}{|l|l|l|}
\hline Antibiotics used & Zone size & Inference \\
\hline Penicillin G & $8 \mathrm{~mm}$ & Resistant \\
\hline Erythromycin & $10 \mathrm{~mm}$ & Resistant \\
\hline Vancomucin & $11 \mathrm{~mm}$ & Resistant \\
\hline Ampicillin & $9 \mathrm{~mm}$ & Resistant \\
\hline Cotrimoxazole & $20 \mathrm{~mm}$ & Sensitive \\
\hline Clindamycin & $16 \mathrm{~mm}$ & Sensitive \\
\hline
\end{tabular}

The isolate was shown to have resistance towards penicillin G, erythromycin, vancomycin and ampicillin. From this, it is inferred that the probiotic strain is unaffected by any of the 4 antibiotics. But cotrimoxazole and clindamycin can be lethal to the isolate, since it is sensitive.

\section{Shelf Life Study}

Fruit juice is considered as an ideal medium for culturing probiotic strains since they naturally contain minerals, vitamins, antioxidants etc. and are pleasing for all age groups. The LAB isolate inoculated into fruit juice was periodically taken and the colony forming (CFU) was determined using spread plate technique. The results are tabulated below.

Table.4 Biochemical Characterization

\begin{tabular}{|c|c|}
\hline TESTS & RESULTS \\
\hline $\begin{array}{c}\text { Sugar fermentation(glucose, } \\
\text { xylose, arabinose, mannitol, } \\
\text { galactose, salicin, sucrose, } \\
\text { mannose, fructose, rhamnose, } \\
\text { sorbitol) }\end{array}$ & $\begin{array}{c}\text { All sugars were fermented with } \\
\text { no gas production }\end{array}$ \\
\hline Indole & negative \\
\hline Methyl red & Positive \\
\hline Voges-prausker & Negative \\
\hline Citrate & Negative \\
\hline Nitrate reduction & Negative \\
\hline Urease & negative \\
\hline Triple sugar iron agar & $\begin{array}{c}\text { Acid slant, acid butt, no gas and } \\
\text { no } \mathrm{H}_{2} \mathrm{~S} \text { production }\end{array}$ \\
\hline Oxidase & negative \\
\hline
\end{tabular}


Table.5

\begin{tabular}{|l|l|}
\hline Day & CFU per ml \\
\hline 3 & TNTC \\
\hline 5 & TNTC \\
\hline 10 & TNTC \\
\hline 13 & TNTC \\
\hline 15 & TNTC \\
\hline 20 & TNTC \\
\hline 25 & TNTC \\
\hline 30 & TNTC \\
\hline
\end{tabular}

The result revealed that the isolate remained alive in the juice for 30 days. It has the ability to survive more than 30 days since the viable count is significantly high.

\section{VITEK Identification}

VITEK is an automated instrument that is used for identifying bacterial species. The result accuracy is achieved when proper conditions are maintained. Through VITEK identification, the LAB isolate was found to be Enterococcus faecium with $87 \%$ probability.

The various tests performed confirms that the organism from curd belongs to Lactic Acid Bacteria, since it is Gram Positive, catalase negative cocci. The bacteria satisfies all the conditions required for a probiotic strain. Also it has the ability to survive in fruit juice for considerably long period of time.

The science around the concept of probiotics continues to expand. Current global research efforts have greatly contributed to the understanding of the role of GI commensal organisms in their extraordinary symbiotic relationship with humans. Continued research into the microbiota will no doubt help lead to an improved insight into the impact of probiotics and prebiotics on human health.

The study proves that Enterococcus faecium is having probiotic properties and is regarded as safe to be used as a probiotic. It satisfies most of the conditions required, but further confirmations are needed. Molecular level of identification also provides effective details about the strain and it is possible to proceed for further experiments.

The organism is sure to affect the host in a positive way by favoring health. The health benefits conferred by the strains are numerous and it is confidential also.

Research is still going on to discover new facts about probiotics. Researchers are in a continuous exploration to deeply understand the mechanisms behind probiotic action.

\section{References}

Ana Lucia, F. Pereira. 2010. Probiotic beverage from cashew apple juice fermented with Lactobacillus casei: 5693.

Arvanitoyannis, I.S., Van HouwelingenKoukaliaroglou, M. 2005. Functional Foods: A Survey of Health Claims, Pros and Cons, and Current Legislation. Crit. Rev. Food sci. Nutr., 45: 385-404.

Anukam, K., E. Osazuwa, I. Ahonkhai, M. Ngwu, G. Osemene, A. W. Bruce, and G. Reid. 2006. Augmentation of antimicrobial metronidazole therapy of bacterial vaginosis with oral probiotic Lactobacillus rhamnosus GR-1 and Lactobacillus reuteri RC-14: Randomized, double-blind, placebo controlled trial. Microbes and Infect., 8:1450-1454.

FAO/WHO. 2001. Joint FAO/WHO Expert 
Consultation on evaluation of health and nutritional properties of probiotics in food including powder milk with live lactic acid bacteria. Cordoba, Argentina, October 2001. http://www.who.int/foodsafety/publicati ons/fs_management/en/probiotics.pdf

United Nations. 2002. Food and Agriculture Organization of the United Nations/World Health Organization (UNFAO/WHO). Guidelines for the Evaluation of Probiotics in Food, http://ftp.fao.org/es/esn/food/wgreport2. pdf (4 October 2006)

U.S. Food and Drug Administration-Center for Food Safety and Applied Nutrition (USFDA- $\quad 2004$. Substantiation for Dietary Supplement Claims Made under Section 403(r) (6) of the Federal Food, Drug, and Cosmetic Act, http://www.cfsan.fda.gov/ dms/ dsclmgui.html (12 February 2007)

\section{How to cite this article:}

Subi Mathew, Sneha Vijay and V.P. Potty. 2017. Assesment of Probiotic Potential of Lactic Acid Bacteria Isolated from Curd and its Application using Fruit Juice. Int.J.Curr.Microbiol.App.Sci. 6(1): 282-289. doi: http://dx.doi.org/10.20546/ijcmas.2017.601.034 